\title{
Incorporation of EGFR mutation status into $M$ descriptor of new TNM classification influences survival curves in non-small cell lung cancer patients
}

\author{
Karmen Stanic ${ }^{1}$, Nina Turnsek², Martina Vrankar ${ }^{1}$ \\ ${ }^{1}$ Department of Radiotherapy, Institute of Oncology Ljubljana \\ ${ }^{2}$ Department of Medical Oncology, Institute of Oncology Ljubljana \\ Radiol Oncol 2019; 53(4): 453-458.
}

Received 1 August 2019

Accepted 30 August 2019

Correspondence to: Asst. Prof. Martina Vrankar, M.D., Ph.D., Institute of Oncology Ljubljana, Zaloška 2, SI-1000 Ljubljana, Slovenia. E-mail: mvrankar@onko-i.si

Disclosure: No potential conflicts of interest were disclosed.

Data from this research have been partly presented as poster at $17^{\text {th }}$ World Conference on Lung Cancer 2016 in Vienna. J Thorac Oncol 2017; 12(Suppl 1): S302.

Background. The 8th edition of tumor node metastasis (TNM) staging system for lung cancer introduced a revision of M descriptor. The limitation of new classification to predict prognosis is its focus on anatomical extent of the disease only. Information on molecular status of the tumor significantly influences treatment response and survival; however, data addressing this issue is scarce. This report points to the impact of epidermal growth factor receptor (EGFR) mutation in non-small cell lung cancer (NSCLC) patients on survival in view of new M descriptors of TNM classification system.

Patients and methods. Medical records of 479 consecutive metastatic NSCLC patients treated between 2009 and 2011, all tested for EGFR mutations, were retrospectively reviewed. For 355 patients medical records included sufficient information to be appropriately categorized into one of the new subgroups according to the $M$ descriptor in 8th TNM classification, of those 89 (25.1\%) patients harboured EGFR mutations (EGFR-m).

Results. Median overall survival (mOS) of EGFR-m patients was significantly longer than mOS of patients without EGFR mutations (20.6 months vs. 8.3 months, $p<0.001$ ). Patients with limited disease burden (M1b sub-group) had the longest mOS among EGFR wild type patients (EGFR-wt) and also among EGFR-m patients, 14.4 months and 39.2 month, respectively. In spite of widespread metastatic disease of Mlc EGFR-m patients, their mOS (18.8 months) was longer than mOS of oligometastatic EGFR-wt patients (MIb), who had the lowest disease burden (14.4 months). Median follow up was 53.9 months.

Conclusions. Incorporation of EGFR mutation status in advanced NSCLC further differentiates survival curves of M categories in $8^{\text {th }}$ TNM classification and more precisely predicts survival compared to number of metastasis or number of metastatic sites alone.

Key words: EGFR mutations; non-small cell lung cancer; survival; metastases; TNM

\section{Introduction}

The 8th edition of tumour-node-metastases (TNM) staging system for lung cancer came into practice in January 2018 and replaced $7^{\text {th }}$ edition from 2007.-3 TNM classification is a coding system for the anatomic extent of the disease. By its definition it does not include tumour markers, genetic signatures, comorbidities etc., which are all known to influence the survival. Nevertheless, the authors of new TNM proposal pointed out improvement in survival curves as one of major reasons for the 
change of classification. Several new diagnostic, imaging and treatment developments were introduced during the period in which patients were included, from 1990 to 2000. New imaging techniques such as PET/CT and MRI influence the stage migration, while the new treatment with targeted agents and immunotherapy influences the survival curves. ${ }^{4-9}$ The majority of new improvements and developments in the last 15 years were implemented for metastatic patients and therefore affected mostly $\mathrm{M}$ descriptor. With new classification there are no changes of M1a category, while there is further sub-classification of M1b category into M1b (single distant metastatic lesion in single organ) and M1c (multiple metastases in one organ or in multiple distant metastatic sites). ${ }^{10}$ There is growing evidence showing that information on molecular tumour status significantly affects treatment response and survival. ${ }^{11-16}$ This report points on impact of epidermal growth factor receptor (EGFR) mutation on survival in view of new TNM classification system.

\section{Patients and methods}

Medical records of 479 consecutive metastatic nonsmall cell lung cancer (NSCLC) patients, treated between 2009 and 2011, all tested for EGFR mutations were retrospectively reviewed. They were categorized into sub-groups according to new $M$ descriptors. For 355 out of 479 patients, among them 89 (25.1\%) with EGFR mutations (EGFR-m), there was sufficient information in medical records

TABLE 1. Baseline characteristics of patients by EGFR mutation status

\begin{tabular}{|c|c|c|c|c|c|c|}
\hline Characteristics & $\begin{array}{c}\text { All } \\
n\end{array}$ & $\begin{array}{c}\text { EGFR-wt } \\
n\end{array}$ & (\%) & $\begin{array}{c}\text { EGFR-m } \\
n\end{array}$ & $(\%)$ & $p$ \\
\hline All patients & 355 & 266 & 75 & 89 & 25 & \\
\hline \multicolumn{7}{|l|}{ Age (years) } \\
\hline median & 64.4 & 63.5 & 65.6 & 65.6 & & 0.98 \\
\hline range & $25-88$ & $25-87$ & $25-87$ & $36-88$ & & \\
\hline \multicolumn{7}{|l|}{ Gender } \\
\hline female & 165 & 107 & 40.2 & 58 & 65.2 & $<0.001$ \\
\hline male & 190 & 159 & 59.8 & 31 & 34.8 & \\
\hline Smoking status & & & & & & $<0.001$ \\
\hline current & 142 & 132 & 49.6 & 10 & 11.2 & \\
\hline former & 101 & 81 & 30.5 & 20 & 22.5 & \\
\hline never & 95 & 40 & 15.0 & 55 & 61.8 & \\
\hline unknown & 17 & 13 & 4.9 & 4 & 4.5 & \\
\hline \multicolumn{7}{|l|}{ Histology } \\
\hline adenocarcinoma & 309 & 232 & 87.2 & 77 & 86.2 & 0.86 \\
\hline non-small cell lungcancer, NOS & 46 & 34 & 12.8 & 12 & 13.5 & \\
\hline \multicolumn{7}{|l|}{ Metastatic sites* } \\
\hline Brain & 86 & 61 & 22.9 & 25 & 28.1 & 0.33 \\
\hline Bone & 151 & 104 & 39.1 & 47 & 52.8 & 0.02 \\
\hline Lung & 157 & 106 & 39.8 & 51 & 57.3 & 0.01 \\
\hline Pleura & 115 & 83 & 31.2 & 32 & 36.0 & 0.48 \\
\hline Liver & 55 & 40 & 15.0 & 15 & 16.9 & 0.68 \\
\hline Adrenal gland & 49 & 43 & 16.2 & 6 & 6.7 & 0.02 \\
\hline Distant lymph nodes & 55 & 46 & 17.3 & 9 & 10.1 & 0.10 \\
\hline Other sites & 40 & 34 & 12.8 & 6 & 6.7 & 0.11 \\
\hline
\end{tabular}

* Sum of all metastasis is more than 355 as some patients had multiple metastases; EGFR-m = patients harboured EGFR mutations; EGFR-wt = EGFR wild type patients 
that allowed appropriate new categorisation according to new TNM classification. Median overall survival was calculated from the date of diagnosis to the death or last follow up and estimated using Kaplan-Meier method. ${ }^{17}$ The association between the EGFR mutation status and the clinico-pathological characteristics of patients were tested using the Mann-Whitney $\mathrm{U}$ (MW-U) or the Kruskal Wallis $\mathrm{H}(\mathrm{KW}-\mathrm{H})$ test. Survival and prognosis was assessed using Cox proportional hazard regression analysis. All $\mathrm{p}$ values reported were based on the two-sided hypothesis. Data was calculated using SPSS v.20 statistical package.

This analysis is part of a retrospective study approved by Institutional Review Board Committee and National Ethics Committee (No.143/1/2011).

\section{Results}

Totally, 355 patients were included in final analysis, of those 89 (25.1\%) were EGFR-m positive. Median age of all patients was 64.4 years (range 2588). Majority were male, current or former smokers and had adenocarcinoma. Data on basic patients' characteristics are listed in Table 1.

The distribution of metastases according to EGFR mutation status differed between the two groups, with metastases to bones and lung being more frequent in EGFR-m patients compared to EGFR wild type (EGFR-wt) patients, while metastases to adrenal gland were less frequent in EGFR-m patients as compared to EGFR-wt patients.

Most of the patients with EGFR-m tumors were primary treated with EGFR tyrosine kinase inhibitors (TKIs) (71 cases, 79\%). Chemotherapy (ChT) was applied to 10 patients as first-line systemic treatment while after progression to ChT treatment with TKI was the most common. Eight patients with EGFR-m tumors did not receive any form of systemic treatment. The reason could not be clearly established from the medical records.

For patients with EGFR-wt tumors, platinum based chemotherapy was the most common form of systemic treatment (150/266 cases, 56.4\%). In 29 patients, TKIs were used for maintenance treatment. In the group of EGFR-wt patients, no systemic treatment was given to 87 patients (33\%) due to bad performance status and comorbidities, while palliative irradiation of symptomatic sites was used in some patients in addition to best supportive care.

We compared mOS of patients with and without systemic therapy according to EGFR mutation

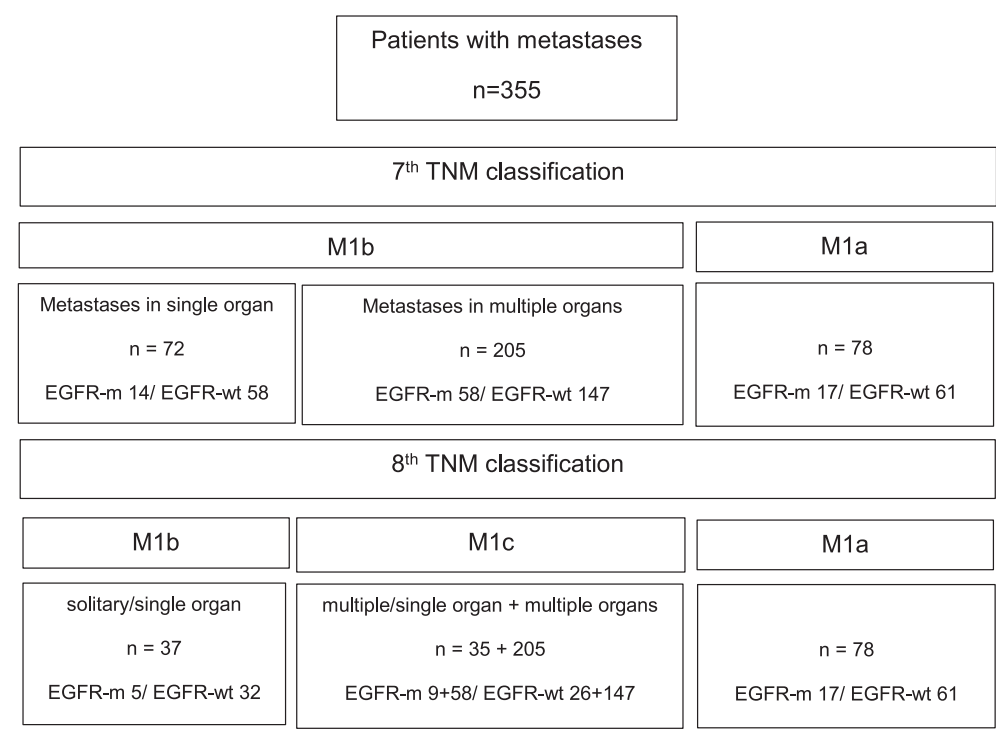

FIGURE 1. Diagram of division: From $7^{\text {th }}$ to $8^{\text {th }}$ TNM classification with incorporation of EGFR mutation status.

EGFR-m = patients harboured EGFR mutations; EGFR-wt = EGFR wild type patients

status. As expected, EGFR-m patients treated with TKI had longer survival than EGFR-m patients on symptomatic treatment only (21.3 vs. 3.3 month), though the number of non-treated patients was too low to draw any firm conclusions. Similarly, EGFR-wt patients who received chemotherapy had longer mOS than those without treatment (12.4 vs. 2.8 months). EGFR-m patients receiving best supportive care only, showed trend to better survival compared to EGFR-wt on best supportive care, but additional analysis was futile due to small number of cases in subcategories.

Patients were first categorized according to $7^{\text {th }}$ TNM classification and according to their EGFR mutation status. Secondly, patients with $7^{\text {th }} \mathrm{M} 1 \mathrm{~b}$ category were grouped to those who had single metastatic site/organ and those with multiple metastases, presented in Table 2.

Finally, we joined cases with multiple metastatic sites and those with multiple metastases in one

TABLE 2. Overall survival of EGFR-m compared to EGFR-wt patients based on the MIb status in $7^{\text {th }}$ TNM classification for single and multiple metastatic sites/organs

\begin{tabular}{lcccccc}
\hline $\begin{array}{l}\text { Metastatic sites } \\
\text { (old M1b only) }\end{array}$ & all & \multicolumn{2}{c}{ EGFR-m } & \multicolumn{2}{c}{ EGFR-w } & p \\
\hline Single organ & $\mathrm{n}$ & $\mathrm{n}$ & $\mathrm{mOS}$ & $\mathrm{n}$ & $\mathrm{mOS}$ & \\
\hline Multiple organs & 72 & 14 & 32.5 & 58 & 11.5 & $<0.001$ \\
All & 205 & 58 & 17.4 & 147 & 6.1 & $<0.001$ \\
\hline
\end{tabular}

EGFR-m $=$ patients harboured EGFR mutations; EGFR-wt $=$ EGFR wild type patients 
TABLE 3. M descriptors for $7^{\text {th }}$ and $8^{\text {th }}$ TNM classification according to EGFR mutation status and their median overall survival (mOS) in months

\begin{tabular}{lcccccc}
\hline \multicolumn{7}{c}{$7^{\text {th }}$ TNM classification } \\
\hline M descriptor & \multicolumn{7}{c}{ EGFR-m } & & \multicolumn{3}{c}{ EGFR-wt } \\
\hline \multicolumn{1}{c}{$\mathrm{n}$} & $\mathrm{n}$ & mOS & $\mathrm{n}$ & mOS & $\mathrm{p}$ \\
\hline Mla & 78 & 17 & 22.4 & 61 & 10.7 & 0.025 \\
Mlb & 252 & 72 & 18.8 & 205 & 7.9 & $<0.001$ \\
All & 355 & 89 & 20.6 & 266 & 8.3 & $<0.001$ \\
\hline $8^{\text {th }}$ TNM classification & \multicolumn{7}{c}{ EGFR-m } & & & EGFR-wt & \\
\hline Mla & 78 & 17 & 22.4 & 61 & 10.7 & 0.025 \\
Mlb & 37 & 5 & 39.2 & 32 & 14.4 & 0.082 \\
Mlc & 240 & 67 & 18.8 & 173 & 6.6 & $<0.001$ \\
All & 355 & 89 & 20.6 & 266 & 8.3 & $<0.001$ \\
\hline
\end{tabular}

EGFR-m = patients harboured EGFR mutations; EGFR-wt = EGFR wild type patients

TABLE 4. Site specific median overall survival (mOS) according to EGFR mutation status

\begin{tabular}{lccccc}
\hline Metastatic site & Patients & \multicolumn{4}{c}{ mOS } \\
\hline & $\mathbf{n}$ & all & EGFR-m & EGFR-wt & $\mathbf{p}$ \\
\hline Brain & 86 & 8.1 & 14.9 & 7.1 & $\mathbf{0 . 0 0 3}$ \\
Bone & 151 & 9.4 & 21.3 & 6.7 & $<0.001$ \\
Lung & 157 & 11.9 & 20.2 & 8.3 & $\mathbf{0 . 0 0 2}$ \\
Pleura & 115 & 8.8 & 20.6 & 6.5 & $<0.001$ \\
Liver & 55 & 5.6 & 10.4 & 5.5 & 0.245 \\
Adrenal gland & 49 & 5.2 & 4.9 & 5.5 & 0.595 \\
Distant lymph nodes & 55 & 6.2 & 13.0 & 5.5 & 0.237 \\
Other sites & 40 & 8.9 & 14.9 & 8.4 & 0.156 \\
\hline
\end{tabular}

EGFR-m = patients harboured EGFR mutations; EGFR-wt = EGFR wild type patients

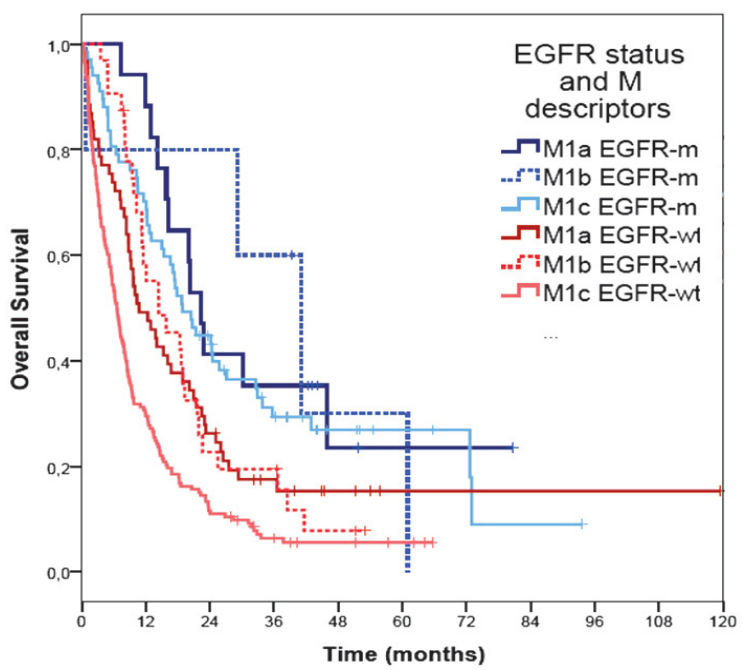

FIGURE 2. Survival curves of different $M$ categories according to EGFR mutation status based on $8^{\text {th }}$ TNM classification.

EGFR-m = patients harboured EGFR mutations; EGFR-wt = EGFR wild type patients organ to form new M1c, incorporating also EGFR mutation status following the process shown in Figure 1.

Survival results show that mOS was better for all metastatic EGFR-m patients compared to metastatic EGFR-wt patients ( 20.6 vs. 8.3 months, $\mathrm{p}<$ 0.001). Detailed mOS for new versus old M descriptor is shown in Table 3.

Patients with metastases to single organ only had better survival than those who had metastases in multiple organs, irrespective of the presence of EGFR mutations (14.4 and 7.9 months, $p=0.006$ ). Significantly better overall survival of EGFR-m patients compared to EGFR-wt patients was seen in group of patients with single organ metastases only as well as in group with metastases in multiple organs $(\mathrm{p}<0.001)$.

Survival curves of different new $\mathrm{M}$ categories (TNM $8^{\text {th }}$ edition) according to EGFR mutation status are presented in Figure 2.

Distribution of metastatic spread to different organs with regard to EGFR mutation status was also analysed. In EGFR-m patients multiple metastases were observed in all organs, the only exception being the adrenal gland where there was only one case with single metastases. On the contrary, EGFR-wt patients had more frequently either one or multiple metastases in single organ. Site specific mOS with regard to EGFR mutation status is shown in Table 4. EGFR-m patients with metastases to brain, bone, lung and pleura have significantly better survival than EGFR-wt patients, while no statistical difference was noted for other metastatic sites.

\section{Discussion}

Our retrospective review analyzed metastatic nonsmall cell lung cancer patients with objective to categorize them according to new $\mathrm{M}$ descriptor incorporating also the data on EGFR mutation status. In the proposal of new M descriptor 1059 metastatic cases were included into detailed survival analysis. ${ }^{10}$ Since the patients were diagnosed between 1999 and 2012, not all could have had EGFR mutation testing, as this was not a routine procedure before the year 2004. ${ }^{18}$ Their main purpose was analysis of expected change in survival curves due to stage migration, incorporating new diagnostic procedures (PET/CT) and new treatment options with local approaches, especially irradiation of oligometastatic sites as well as improvement in systemic treatment, mainly molecular targeted agents. ${ }^{19} \mathrm{In}$ 
our single institution analysis 355 patients were included, which represent one third (35.5\%) of cases published in a paper that is proposing and justifying the classification changes.

In further detailed analysis of distribution pattern of metastatic spread according to EGFR mutation status, we first divided patients by organ/site they metastasized to rather than number of metastasis in a single organ. As shown in this analysis and known also from clinical practice and previous studies, patients with single metastatic site (organ) have better prognosis than those with multiple metastatic sites..$^{20}$ Patients with low number of metastatic sites are known to have oligometastatic disease, though the definitions differ and current guidelines propose modified treatment. ${ }^{21-23}$ The new $\mathrm{M}$ descriptor does not define oligometastatic disease in a way that would help clinicians make decision about the treatment. For example, treatment and prognosis of patients with one metastasis in the brain (M1b) might be the same as of three small metastases (M1c). ${ }^{24}$ Similarly, treatment of one metastasis in the liver (M1b) will probably be the same as for multiple metastases (M1c). One special situation is metastasis to the adrenal gland. Therapeutic options for metastasis to the adrenal gland as a single metastatic site are local treatments, either irradiation or operation. ${ }^{25,26} \mathrm{No}$ cases with more than one metastasis in a single adrenal gland were observed in the current analysis. Patients with metastases in the adrenal gland, which are often affected on both sides, have bad prognosis and survival. According to our analysis, patients with metastases to adrenal gland have the worst survival regardless of EGFR-m status. In addition, other researchers noticed that patients with adrenal gland metastasis showed impaired survival. ${ }^{10}$ However, based on their data they concluded that the site of metastasis is not prognostic for single or multiple lesions within the single organ. It is questionable whether one or more metastases in a single organ really influence survival. On the contrary, current analysis suggests that the number of metastatic sites might be more important prognostic factor than number of metastatic lesions in one organ.

Even though large number of patients was included in our series, only 5 patients with EGFR mutations were sub-classified into M1b category. It seems that once EGFR-m tumors metastasize they do it in aggressive and widespread way. For the first time we have shown that not only have EGFR-m patients better mOS than EGFR-wt patients but also better mOS in each sub-category of
$\mathrm{M}$ descriptor. This analysis showed that in spite of widespread metastatic disease (M1c) and high tumor burden, EGFR-m patients treated with TKI had longer mOS (18.8 months) than EGFRwt patients with only one metastasis (M1b) (14.4 months). Likely, EGFR-m status has greater impact on survival curves than different sub-categories of $\mathrm{M}$ descriptor.

We are aware of the need for simple and predictable system for classification in prognostic groups of patients with lung cancer. However, according to our survival data it seems that TNM classification is inadequate for relevant prediction of survival, because in some cases, as we show for EGFR mutations, molecular feature is more important than anatomical distribution of malignant disease. Maybe we should consider adding the new descriptor to TNM classification that labels molecular feature of tumor. Recently, investigators from University of California published an article on how integration of molecular prognostic classifier into TNM system might improve identification of high-risk patients and predict survival in non-metastatic NSCLC. They used 11 cancer-related target genes; however, they did not include current biomarkers such as EGFR, KRAS ALK, which was recognized as an important drawback of their study. ${ }^{27}$

There are some important limitations to the current analysis. It was not possible to find reliable metastatic information for about $25 \%$ of cases in our database, which could not be included in the analysis. It should be recognized that due to small number of series those might be the cases that could influence the results and represent the potential bias. There were also more patients with symptomatic treatment among EGFR-wt patients than EGFR-m patients, reflecting real clinical situation. However, this is not surprising as majority of EGFR-m patients are nonsmokers and have less comorbidities. Also, in contrast to EGFR-wt patients who can receive chemotherapy only in good performance status (PS) 0-2, EGFR-m patients may also receive TKI in poor PS (3-4). Due to retrospective nature of the study not all metastatic sites rather symptomatic ones were diagnosed and collected in routine clinical practice.

\section{Conclusions}

Number of metastatic sites might be more important predictive survival factor than number of metastatic lesions in single organ, though both fall into M1c category. Incorporation of EGFR mutation sta- 
tus seem to predict survival more reliably than the number of metastasis or number of metastatic sites in NSCLC. Our results indicate that further analysis with incorporation of information on also other molecular status is warranted to further improve differentiation of survival curves in the future.

\section{References}

1. Brierly DJ, Gospodarowicz MK, Witekind C, editors. TNM classification of malignant tumours. 8th edition. Oxford: Wiley-Blackwell; 2017. p. 114-20.

2. Sobin LH, Gospodarowicz MK, Witekind C, editors. TNM classification of malignant tumours. 7th edition. Oxford: Wiley-Blackwell; 2009. p. 138-46.

3. Goldstraw P, Crowley J, Chansky K, Giroux DJ, Groome PA, Rami-Porta R, et al. The IASLC Lung Cancer Staging Project: proposals for the revision of the TNM stage groupings in the forthcoming (seventh) edition of the TNM classification of malignant tumours. J Thorac Oncol 2007; 2: 706-14. doi: 10.1097/JTO.0b013e31812f3c1a

4. Kligerman S, Digumarthy S. Staging of non small cell lung cancer using integrated PET/CT. AJR Am J Roentgenol 2009; 193:1203-11. doi: 10.2214/ AJR.09.3193

5. Kim SY, Kim JS, Park HS, Cho MJ, Kim JO, Kim JW, et al. Screening of brain metastasis with limited magnetic resonance imaging (MRI): clinical implications of using limited brain MRI during initial staging for non-smal cell lung cancer patients. J Korean Med Sci 2005; 20: 121-6. doi: 10.3346/ jkms.2005.20.1.121

6. Rami-Porta R, Asamura H, Goldstraw P. Predicting the prognosis of lung cancer: the evolution of tumor, node and metastasis in the molecular agechallenges and opportunities. Trans/ Lung Cancer Res 2015; 4: 415-23. doi: 10.3978/j.issn.2218-6751.2015.07.11

7. Huang $A$, Li R, Zhao J, Wang $X$, Jin $B, N i u ~ Y$, et al. Epidermal growth factor receptor (EGFR)-tyrosine kinase inhibitors combined with chemotherapy in first-line treatment in an advanced non-small cell lung cancer patient with EGFR sensitive mutation. Thorac Cancer 2016; 7: 614-8. doi: 10.1111/17597714.12364

8. Park HJ, Oh HJ, Kim KH, Kim TO, Park CK, Shin HJ, et al. Quantification of epidermal growth factor receptor (EGFR) mutation may be a predictor of EGFR-tyrosine kinase inhibitor treatment response. Thorac Cancer 2016; 7: 639-47. doi: 10.1111/1759-7714.12378

9. Reck M, Rodríguez-Abreu D, Robinson AG, Hui R, Csőszi T, Fülöp A, et al. Pembrolizumab versus chemotherapy for PD-L1-positive non-small-cell lung cancer. N Engl J Med 2016; 375: 1823-33. doi: 10.1056/NEJMoa1606774

10. Eberhardt WEE, Mitchell A, Crowley J, Kondo H, Kim YT, Turrisi A 3rd, et al. The IASLC Lung Cancer Staging Project Proposals for the revision of the $\mathrm{M}$ descriptors in the forthcoming eighth edition of the TNM classification of lung cancer. Thorac Oncol 2015; 10: 1515-22. doi: 10.1097/ JTO.0000000000000673

11. Stanic K, Zwitter M, Hitij NT, Kern I, Sadikov A, Cufer T. Brain metastases in lung adenocarcinoma: impact of EGFR mutation status on incidence and survival. Radiol Oncol 2014; 48: 173-83. doi: 10.2478/raon-2014-0016

12. Soria JC, Tan DSW, Chiari R, Wu YL, Paz-Ares L, Wolf J, et al. First-line ceritinib versus platinum-based chemotherapy in advanced ALK-rearranged nonsmall-cell lung cancer (ASCEND-4): a randomised, open-label, phase 3 study. Lancet 2017; 389: 917-29. doi: 10.1016/S0140-6736(17)30123-X

13. Duruisseaux M, Besse B, Cadranel J, Pérol M, Mennecier B, Bigay-Game $L$, et al. Overall survival with crizotinib and next-generation ALK inhibitors in ALK-positive non-small-cell lung cancer (IFCT-1302 CLINALK): a French nationwide cohort retrospective study. Oncotarget 2017; 8: 21903-17. doi: 10.18632/oncotarget.15746

14. Soria JC, Ohe Y, Vansteenkiste J, Reungwetwattana T, Chewaskulyong B, Lee $\mathrm{KH}$, et al. Osimertinib in untreated EGFR-mutated advanced non-small-cell lung cancer. N Engl J Med 2018; 378: 113-25. doi: 10.1056/NEJMoa1713137
15. Lee CK, Man J, Lord S, Cooper W4, Links M, Gebski V, et al. Clinical and molecular characteristics associated with survival among patients treated with checkpoint inhibitors for advanced non-small cell lung carcinoma: a systematic review and meta-analysis. JAMA Oncol 2018; 4: 210-16. doi: 10.1001/jamaoncol.2017.4427

16. Kaderbhaï C, Tharin Z, Ghiringhelli F. The role of molecular profiling to predict the response to immune checkpoint inhibitors in lung cancer. Cancers (Basel) 2019; 11: E201. doi: 10.3390/cancers11020201

17. Kaplan EL, Paul Meier. Nonparametric estimation from incomplete observations. Journal of the American Statistical Association 1958; 53: 457-81.

18. Rami-Porta R, Goldstraw P. Strength and weakness of the new TNM classification for lung cancer. Eur Respir J 2010; 36: 237-9. doi: 10.1183/09031936.00016210

19. Doroshow DB, Herbst RS. Treatment of advanced non-small cell lung cancer in 2018. JAMA Oncol 2018; 4: 569-70. doi: 10.1001/jamaoncol.2017.5190

20. Hendriks LE, Derks JL, Postmus PE, Damhuis RA, Houben RM, Troost EG, et al. Single organ metastatic disease and local disease status, prognostic factors for overall survival in stage IV non-small cell lung cancer: results from a population-based study. Eur J Cancer 2015; 51: 2534-44. doi: 10.1016/j. ejca.2015.08.008

21. National Comprehensive CancerNetwork. Non-small cell lung cancer National Comprehensive Cancer Network Guidelinese. v.5. 2018. [cited 2018 Jul 25]. Available at: http://www.nccn.org/professionals/physician $\mathrm{gls} / \mathrm{pdf} / \mathrm{nscl} . \mathrm{pdf}$

22. Novello S, Barlesi F, Califano R, Cufer T, Ekman S, Levra MG, et al. Metastatic non-small-cell lung cancer: ESMO Clinical Practice Guidelines for diagnosis, treatment and follow-up. Ann Oncol 2016; 27(Suppl 5): v1-27, 2016. doi: 10.1093/annonc/mdw326

23. Folkert MR, Timmerman R. Review of treatment options for oligometastatic non-small cell lung cancer. Clin Adv Hematol Oncol 2015; 13:186-93. PMID: 26352427

24. Sperduto PW, Yang TJ, Beal K, Pan H, Brown PD, Bangdiwala A, et al Estimating survival in patients with lung cancer and brain metastases: an update of the graded prognostic assessment for lung cancer using molecular markers (Lung-molGPA). JAMA Oncol 2017; 3: 827-31. doi: 10.1001/ jamaoncol.2016.3834

25. Miyaji N, Miki T, Itoh Y, Shimada J, Takeshita T, Churei H, et al. Radiotherapy for adrenal gland metastasis from lung cancer: report of three cases. Radia Med 1999; 17: 71-5. PMID: 10378656

26. Pardo Aranda F, Larrañaga Blanc I, Rivero Déniz JR, Trujillo JC, Rada Palomino A, García-Olivares E, et al. Surgical treatment of lung cancer with synchronous adrenal metastases: adrenalectomy first. Cir Esp 2017; 95: 97101. doi: 10.1016/j.ciresp.2017.01.003

27. Kratz JR, Haro GJ, Cook NR, He J, Van Den Eeden SK, Woodard GA, et al. Incorporation of a molecular prognostic classifier improves conventional non-small cell lung cancer staging. J Thorac Oncol 2019; 14: 1223-32. doi: 10.1016/j.jtho.2019.03.015 